\section{UCDNN}

LIBRARY
University of Connecticut OpenCommons@UConn

June 2005

\title{
Enterococcus Spp. in Endodontically Treated Teeth With and Without Periradicular Lesions
}

Blythe Kaufman

Follow this and additional works at: https://opencommons.uconn.edu/sodm_masters

\section{Recommended Citation}

Kaufman, Blythe, "Enterococcus Spp. in Endodontically Treated Teeth With and Without Periradicular Lesions" (2005). SoDM Masters Theses. 64.

https://opencommons.uconn.edu/sodm_masters/64 


\title{
Enterococcus Spp. in Endodontically Treated Teeth With and Without
} Periradicular Lesions.

\author{
Blythe Kaufman D.M.D.
}

B.S., Providence College, 1998

D.M.D., University of Connecticut, 2002

\author{
A Thesis \\ Submitted in Partial Fulfillment of the \\ Requirements for the Degree of \\ Masters of Science \\ at the \\ University of Connecticut \\ 2005
}




\title{
APPROVAL PAGE
}

\begin{abstract}
Master of Science Thesis
Enterococcus Spp. in endodontically treated teeth with and without periradicular lesions.
\end{abstract}

Presented by

Blythe Kaufman D.M.D.

Major Advisor

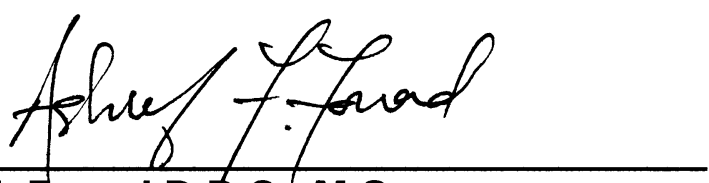

Ashraf F. Fouad D.W.S., M.S.

Associate Advisor $\frac{1}{\text { Larz Spengerg D.D.S., Ph.D! }}$.

Associate Advisor T. Fir

Kamran Safavi D.M.D., M.Ed.

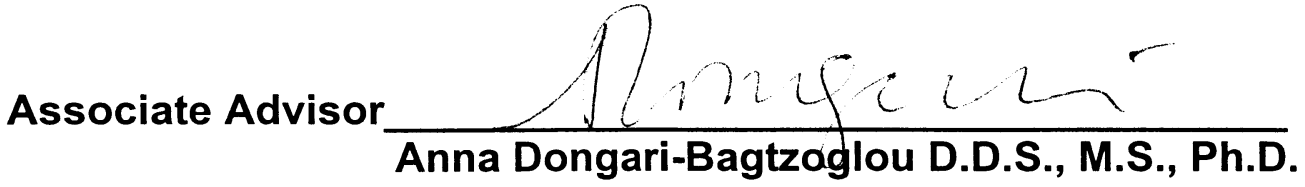

University Of Connecticut

2005 


\section{Acknowledgement}

I would like to acknowledge Dr. Fouad, my major advisor, who provided direction and mentorship throughout the research process. He challenged me to strive beyond merely completing a research project; the research itself became exciting and sharing our findings with the endodontic community was remarkably rewarding.

Dr. Spångberg thank you for mentoring me as a dental student and exposing me to endodontics. Thank you also for initially proposing the question that developed into my masters thesis.

I will always thank Dr. Safavi for providing a caring clinical role model. Your belief in me as a clinician and surgeon has given me the confidence I now carry while treating patients.

I would like to thank Dr. Dongari for her assistance with my thesis.

Special thanks to all my co-residents for their help gathering clinical cases.

Finally, I would like to thank my husband Dr. Seth Kaufman for his patience and support. 
TABLE OF CONTENTS

Page

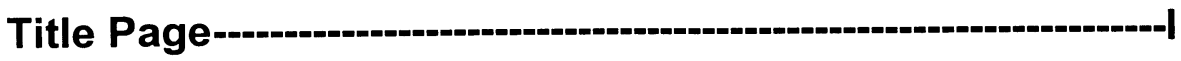

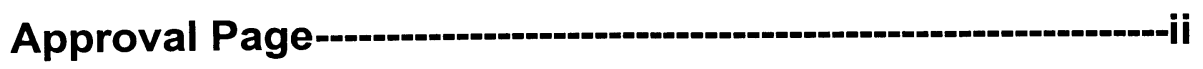

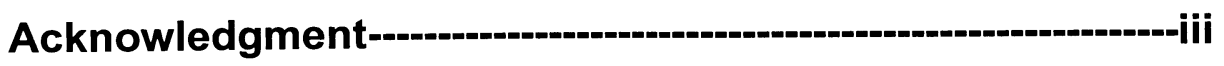

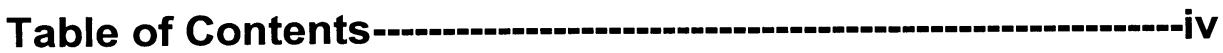

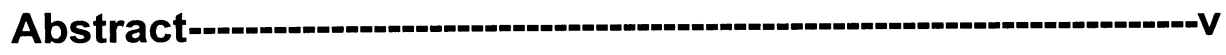

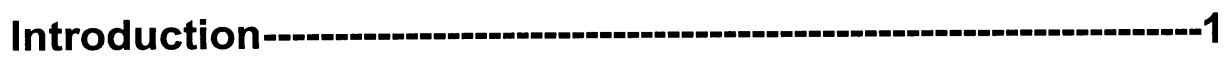

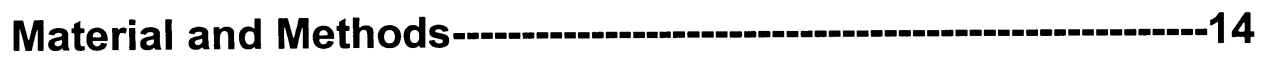

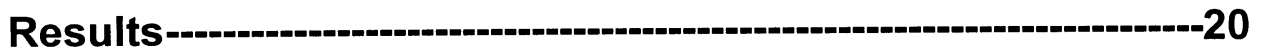

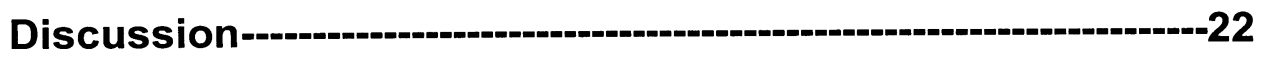

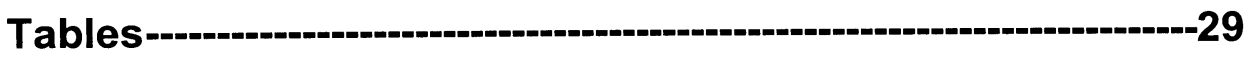

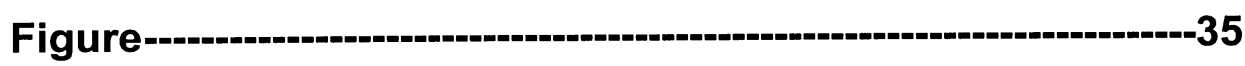

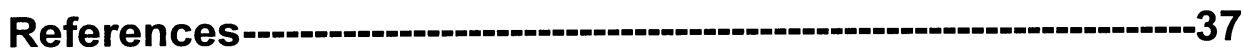




\begin{abstract}
The purpose of this study was to determine if Enterococcus spp. are more prevalent in endodontically-treated teeth with periradicular lesions compared with teeth that require retreatment but have no periradicular rarefaction. Fifty-eight teeth which had received root canal therapy more than one year previously and required retreatment were included.. Designation of lesion vs. no lesion was determined by two experienced endodontists. DNA extraction and PCR amplification were performed using ubiquitous $16 \mathrm{~S}$ rDNA bacterial primers, as well as Enterococcus spp.-specific primers. The results showed that the overall prevalence of bacteria was $90 \%$ and Enterococcus spp. was $12 \%$. Chi-square analysis revealed a statistically significant relationship between the presence of a lesion and the presence of bacteria, as detected by the universal primers $(p=.032)$. Using logistic regression, a statistically significant relationship was found between teeth with normal periapex and the presence of Enterococcus spp. $(p=.023)$. This study revealed that bacteria are significantly associated with endodontic treatment failure but enterococci are not associated with disease.
\end{abstract}




\section{INTRODUCTION}

\section{Bacterial etiology of periapical lesion}

Microbiology and endodontics are intimately related. Microbiological aspects of the root canal space must be considered of equal importance to that of the technical challenges present when instrumenting and filling the root canal space. Without such a blend of the two modalities successful therapy cannot be obtained. However, decisive scientific evidence to support the true importance of bacteria in the development of periapical disease did not exist before 1965 (Kakehashi et al. 1965). Prior to this date, only associations had been established between root canal failure and microorganisms. Early pioneers such as Onderdonk recognized bacterial implications and advocated culturing before filling root canals. He also recommended two visits prior to obturation (Onderdonk 1901). In 1906, Buckley, advocated changing a dressing of

formocreosol several times until no pus was present prior to obturation (Buckley 1906). However, there were still misconceptions regarding the etiology of endodontic failure. Blayney described three causes of failure: introduction of outside infection, traumatization of remaining tissue by careless handling and lastly the use of irritating drugs (Blayney 1927).

Conclusive evidence to support a causitive relationship between bacteria and periapical disease was documented in an experiment by Kakehashi et al (1965). Kakehashi demonstrated through an animal model that germ free rats did not develop pulp necrosisi or periapical lesions when their pulps were mechanically exposed whereas pulps exposed in rats with a normal bacterial 
flora did develop periapical rarefactions. Exposure of the pulp alone did not cause periapical disease. Bacteria were the critical piece needed to trigger the cascade of events that culminates in periapical breakdown (Kakehashi et al. 1965).

This study was followed in close succession by Torneck in 1966 who disproved the hollow tube effect proposed by Rickert and Dixon in 1931. He repeated their study with an important modification. He used a rat model instead of a rabbit and instead of placing the hollow tubes in an area of significant friction tubes were placed into the dorsal subcutaneous tissue. The sterile inert polyethylene tubules induced little or no inflammation (Torneck 1966). However, when necrotic tissue inoculated with gram-negative cocci was placed in the tubes severe inflammation with abscess formation was noted (Torneck 1967).

A monkey study demonstrated the influence of indigenous oral bacteria and necrotic pulp tissue on the periapical health (Moller et al. 1981). Seventyeight teeth were aseptically necrotized. Fifty-two of the 78 teeth were infected with autogenous oral flora while the remainder were left bacteria free. The monkeys were followed for 6 to 7 months. At the conclusion of the study all of the 52 teeth that were infected developed apical periodontitis. The remaining 26 teeth which were still sterile had no signs of periapical inflammation. The conclusion from this study is that sterile necrotic tissue is benign in itself; it is the bacteria that induce periapical breakdown. Dahlen and Bergenholtz also appreciated the importance of certain bacteria in the development of periapical 
disease; necrotic tissue alone cannot cause or maintain periapical osteolysis (Dahlen and Bergenholtz 1980).

\section{Origin of endodontic infections}

The source of the bacteria became a debate. Through the 1940's and extending into the late 1950's the theory of anachoresis wa dominating the field (Robinson and Boling 1941; Gier and Mitchell 1968; Delivanis and Fan 1984). This theory stated that microorganisms reach necrotic pulps via the blood stream. However, several studies disproved this notion (Moller et al. 1981). Many other theories persist regarding how teeth initially become infected; the most obvious one is direct exposure of the pulp to the oral cavity, while other modes of entry include open dentinal tubules, accessory canals or cracks.

With the predominant avenue of bacterial entry into the pulp via caries and exposed dentin established the next most important question is which bacteria comprise the primary infection. Initially an exposure of the surface region of the pulp to the oral cavity will result in a surface infection predominated by aerobic bacteria. The first bacteria to invade the pulp are gram positive. However, gram negative facultative anaerobes increase in number over time and out number the aerobic population (Sundqvist 1992). A continuum exists whereby the flora begins to shift in the apical region in a closed environment. A decrease in oxygen tension selects for obligate anaerobes (Sundqvist 1992) and as the periapical disease progresses the flora of the untreated tooth is comprised of approximately 
90\% strict anaerobes (Sundqvist 1976; Bystrom and Sundqvist 1981; Haapasalo 1989; Sundqvist et al. 1989).

\section{Bacterial species associated with periapical pathology}

Although many bacteria are able to stimulate periapical inflammation certain bacteria and combinations of bacteria are more potent. In an attempt to prove Koch's postulate, Sundqvist and co-workers found that only a combination of bacteria isolated from an infected root canal not a single species could induce transmissible infection in an animal model (Sundqvist et al. 1979). Transmission was further facilitated by certain species present in the samples. Successful transmission was achieved when combinations of $P$. intermedia or $P$. endodontalis were present (Sundqvist et al. 1979). Thus, through successful transmissioin one of Koch's postulates was fulfilled. Sundqvist's findings have been replicated by others(van Winkelhoff et al. 1985). In addition to $P$. intermedia and $P$. endodontalis, $P$. gingivalis was also found to be a major component in the mixed infection seen in endodontic abscesses (van Winkelhoff et al. 1985).

There is also a certain profile of bacteria associated with exacerbations and drainage. Porphyromonas species are associated with development of exacerbations. In an in vivo study of 72 teeth with periapical rarefactions 17 cases had exacerbations. Among those 17 cases with acute abscesses $90 \%$ were associated with recovery of Porphyromonas (Sundqvist et al. 1989).

A relationship exists between the number of strains found in a root canal and symptomatology. In a clinical study of 16 necrotic teeth with intact crowns all 
7 painful cases had six or more species present within the root canal (Sundqvist 1976). The 9 cases without pain had fewer than 6 species present within the root canal space. There also seems to be an association between lesion size and the number of strains present. Of the 9 teeth with a periapical lesion greater than or equal to $5 \mathrm{~mm}, 8$ of them had at least 5 strains present. Likewise, 8 of the 9 teeth with lesions measuring less than $5 \mathrm{~mm}$ had fewer than 6 strains of bacteria present (Sundqvist 1976). Thus, it would seem, a threshold that must be reached where a certain bacterial load or quantity of bacterial strains must be present to induce significant osteolysis and clinical symptoms.

\section{Therapeutic endpoint}

Eradication of the bacteria within the root canal space has posed a formidable challenge. Calcium hydroxide has been shown to eliminate most microorganisms when used as a 7-day dressing (Sundqvist et al. 1998). A comparison between the antimicrobial effects of calcium hydroxide and iodinepotassium iodide $(\mathrm{IKI})$ in a clinical study revealed that fewer culture reversals occurred when calcium hydroxide was used compared with IKI (Safavi et al. 1985).

If these bacteria are not eradicated during the initial instrumentation and root filling process, the long-term prognosis decreases (Engström et al. 1964; Heling and Shapira 1978; Sjögren et al. 1997). Engström followed 306 cases treated by students in which root canals were performed. Prior to obturation cultures were taken. The observation period was between 4-5 years. He found 
that teeth without pre-operative radiolucencies and with a negative culture at the time of obturation had the best prognosis. The success rate for this group reached $96.1 \%$. The prognosis dropped to $87 \%$ if the tooth without a preoperative radiolucency had a postitive culture. The group with the worst prognosis were those teeth with both a pre-operative lesion and bacteia present.

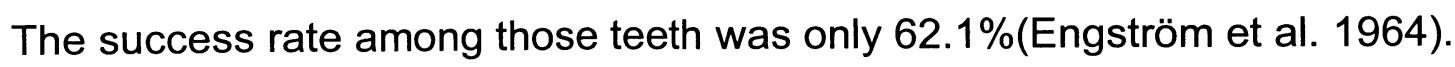

Heling had a similar study, where he treated 118 teeth with repeated cultures taken prior to obturation. Teeth were followed from 1-5 years. The mean success rate for root canal treatment was $78 \%$. Teeth that had a negative culture prior to obturation had an $80 \%$ success rate while teeth with a positive culture had a $70 \%$ success rate. Interestingly, sterility of the root canal influenced the rate of success as time increased. The rate of success was $74 \%$ for teeth with a negative culture at recalls performed 1-3 years post obturation. The success rate dramatically increased at the $4-5$ year recall to $86 \%$ for teeth with a negative culture. This is in contrast to the group of patients with a positive culture at the time of obturation, the success rate of those teeth decreased from $73 \%$ at the $1-3$ year recall to $60 \%$ at the $4-5$ year recall.

The early studies by Engstöm et al. and Heling et al. utilized a traditional culture technique as a means of identifying if bacteria were present while Sjögren used an advanced anaerobic sampling technique of identifying bacteria. Despite the more advanced identification technique the results borne out in the Sjögren data echo those of Engstöm and Heling. Sjögren found that 5 years post obturation teeth that were free of bacteria at the time of root filling had a success 
rate $26 \%$ percentage points higher than those that had bacteria present at the time of root filling (Sjögren et al. 1997).

There is considerable literature to substantiate the effect of root filling length on prognosis. Sjögren found that slight overfills had no influence on outcome. All of the overfills in his sample were successful at the 5 year follow-up (Sjögren et al. 1997). However, Heling showed that overfills had the lowest success rate irregardless of bacteria presence at the time of obturation. Success rate of teeth overfilled was $73 \%$. Obturations flush and underfilled had a success rate of 80 and $82 \%$, respectfully (Heling and Shapira 1978). A subtle distinction may exist regarding the importance of overfills on prognosis, this is most clearly evident in Stringberg's thesis where he distinguishes between slight and substantial overfills. He found that teeth with a pronounced overfill had a significantly lower proportion of successful root fillings than teeth with only a slight overfill at 4 years follow-up (Strindberg 1956).

The work by Engström highlights that overfills are particularly detrimental if bacteria are present at the time of obturation. He found the success rate for teeth with an overfill and bacteria present was only $58.6 \%$ If the obturation was flush or short but bacteria were present the prognosis rose to $78.8 \%$. If the overfill was done aseptically and no bacteria were present at the time of obturation than a success rate of $90 \%$ was possible (Engström et al. 1964).

Sjögren looked at the importance of length on both necrotic cases and retreatment cases (Sjögren et al. 1990). He found necrotic teeth obturated between 0-2 $\mathrm{mm}$ of the radiographic apex had the highest success rate. Success 
rate dropped from $94 \%$ to $76 \%$ if extrusion was present and dropped even further to $68 \%$ if the obturation material was more than $2 \mathrm{~mm}$ short. A similar pattern existed among retreatment cases. Obturation cases $0-2 \mathrm{~mm}$ of the radiographic apex had a success rate of $67 \%$ while teeth with extrusion had a $50 \%$ success rate and those $>2 \mathrm{~mm}$ short had $65 \%$ success rate (Sjögren et al. 1990). Thus it can be surmised that obturations $0-2 \mathrm{~mm}$ short of the apex are optimal. Deviations from the ideal decrease prognosis especially if bacteria are present.

Persistent infection following root canal preparation has been considered the main etiologic factor in root canal failure (Sjögren et al. 1997; Sundqvist et al. 1998). Some have also speculated that re-infection via coronal microleakage may also contribute to failure of endodontic treatment (Ray and Trope 1995; Fouad and Burleson 2003). Investigators have examined the bacterial profile of root-filled teeth with periradicular periodontitis in an attempt to isolate the primary microorganisms responsible for these failures. When the bacterial flora of root filled teeth with periradicular rarefactions is compared to untreated teeth with apical pathosis, the profiles are remarkably different (Sundqvist et al.

1998).Teeth with primary infection have higher numbers of black pigmented Gram-negative obligate anaerobes (Sundqvist 1994), while root filled teeth with periradicular lesions have significantly fewer black pigmented rods and more Gram-positive facultative anaerobic bacteria. Specific culture assays have found that the bacterial species Enterococcus faecalis is present in root filled teeth with periradicular periodontitis approximately $37 \%$ of the time (Sundqvist et al. 1998). 
Table 1 shows a complete list of culture studies that report on the frequency of $E$. faecalis in retreatment cases with apical pathology.

More sensitive polymerase chain reaction techniques have just recently reported the frequency of Enterococcus faecalis in root filled teeth with periradicular rarefactions to be as high as $77 \%$ (Siqueira Junior 2004). However, this high recovery rate may be an outlier among the majority of studies. Rolph et al. showed that Enterococcus spp. were not recovered within their sample of 11 retreatment cases(Rolph et al. 2001). Likewise, recent data from our lab revealed a prevalence of $22 \%$ among retreatment cases (Fouad and Barry 2005). See Table 2 for a complete list of molecular studies and their reported frequencies of Enterococcus recovery among therapy resistant cases.

If Enterococcus faecalis is associated with a higher incidence of root canal failure then eradicating these bacteria and preventing them from repopulating obturated root canals would be a primary objective of retreatment. Studies have shown that Enterococcus faecalis is relatively resistant to many conventional intracanal medicaments. Calcium hydroxide, a standard intracanal medicament, has proven to be ineffective at completely eradicating this bacterial species (Orstavik and Haapasalo 1990; Chavez de Paz Villanueva 2003). Calcium hydroxide exerts most of its antimicrobial effect through its alkalinity (Tronstad et al. 1980). The high pH destroys cell membranes and is not compatible with bacterial viability over a pH of 9.5 (Fisher and Huerta 1984). However, E. faecalis has the ability to withstand a pH of 11.1 (Evans et al. 2002). It was initially thought that there was an inducible stress response mechanism that provided 
protection for $E$. faecalis to calcium hydroxide. It was believed that an initial exposure of calcium hydroxide was necessary to confer protection at subsequent exposures. However, it was shown that pre-treatment with calcium hydroxide $\mathrm{pH}$ 10.3 did not induce tolerance to further exposure at pH 11.5 (Evans et al. 2002). Blockage of protein synthesis did not affect cell survival. However, addition of a proton pump inhibitor produced dramatic reduction in E. faecalis cell survival in the presence of calcium hydroxide. The believed mechanism for evasion of the killing effect of calcium hydroxide is a proton pump that acidify the cytoplasm and allows E.faecalis to live in high pH environments (Evans et al. 2002).

Attempts have been made to use less conventional medicaments and irrigants such as Chlorhexidine (CHX) (Zerella 2003; Siren 2004), lodine potassium iodide (IKI), tetracycline (Dahlen et al. 2000), ozone (Hems et al. 2005) and the recently-described mixture of tetracycline analogue, citric acid, and detergent (MTAD)(Shabahang 2003). While calcium hydroxide alone appears to be ineffective at eradicating $E$. faecalis in vivo, researchers have hypothesized that adding additional agents such as antibiotics, shown to have effectiveness against these bacteria, may be a logical solution. Calcium hydroxide when used as a dressing has been shown to eliminate most microorganisms (Sundqvist et al. 1998) and therefore would be a valuable medicament to continue to use in the root canal system. The addition of erythromycin targeted specifically for $E$. faecalis may represent a comprehensive approach. An in vivo study measuring the effectiveness of tetracycline or erythromycin mixed with calcium hydroxide found antimicrobial effectiveness against Enterococcus to be $79 \%$ and $96 \%$, 
respectively. However, the total antimicrobial effect against the mixed infection present within the root canal was considerably lower. The tetracycline mixture had only a $54 \%$ effectiveness and the erythromycin mixture only $56 \%$. Thus, the overall antimicrobial effect of these agents was weak although erythromycin may show promise as a medicament to target monoinfections of Enterococcus (Molander and Dahlen 2003).

A recent study explored an antimicrobial agent not traditionally used in contemporary endodontics, ozone, which is a powerful oxidizing agent. It has been used as a hospital disinfectant and at water treatment facilities to kill bacteria. An in vitro model to simulate a planktonic and biofilm infection comprised of Enterococcus faecalis was utilized. Although the ozone did reduce viability of $E$. faecalis in the planktonic suspension it had little effect on bacteria in the biofilm (Hems et al. 2005).

A group in New Zealand has also explored additional antibacterial agents not currently being used in endodontics. They have turned their attention to nisin which is a naturally occurring antimicrobial peptide and has been used extensively in food preservation. It is an interesting candidate because it has a benign effect on humans but also has a detrimental interaction with the phosholipid membrane of target bacterial cells. In an in vitro model designed to simulate radicular infection the antimicrobial effect of nisin was evaluated compared to conventional calcium hydroxide. Nisin was effective at eradicating E. faecalis in pure cultures, however, it only reduced $E$. faecalis in canal wall 
radicular dentin by $48 \%$; calcium hydroxide had a similar result only reducing $E$. faecalis by $45 \%$ (Turner et al. 2004).

Some practitioners have incorporated iodine into their arsenal of antimicrobial irrigants. lodine has the advantage of having low tissue toxicity. It exerts its antimicrobial effect by acting as an oxidizing agent and reacting with sulfhydryl groups of bacterial enzymes resulting in disulfide linkages. The major disadvantage of iodine is allergic reactions in some patients. lodine does not lend itself to placement as an intracanal medicament due to its short duration of antimicrobial action. lodine has shown considerable promise as an antibacterial agent targeted toward E. faecalis eradication. Peciuliene and coworkers demonstrated that when a chemo-mechanical preparation is followed by a 5 minute flush of IKI $87.5 \%$ of teeth, which initially tested positive for enterococcus, where rendered free of cultivable enterococcus (Peciuliene et al. 2001).

Some have postulated that the addition of a surfactant to iodine products may improve on the antimicrobial actions by reducing the surface tension. When $2 \%$ iodine potassium iodide $(\mathrm{IKI})$ was compared with Betadine scrub, a povidoneiodine solution with surfactant, using a modified Haapasalo and Orstavik dentinal infection model, both $\mathrm{IKI}$ and Betadine Scrub used as a 24 hour dressing were able to render $90 \%$ of enterococcus infected samples sterile. However, Betadine was significantly less effective as a 15 minute irrigant than IKI (Baker et al. 2004). Thus, addition of surfactant did not improve the efficacy of iodine containing agents against in vitro enterococcal infections. 
The multitude of agents researchers have tried to eliminate this bacteria underscores the tenacity of $E$. faecalis to persist in the root canal system.

\section{Role of $E$. faecalis in the pathogenisis of pereiapical lesions}

The available data remain equivocal as to whether Enterococcus spp. are causative of endodontic failures, or opportunistic bacteria that populate the treated root canal because the environment is conducive to their survival. In this regard, there is little clinical data available regarding the prevalence of Enterococcus spp. in root filled teeth without periradicular rarefactions. Molander and coworkers (Molander et al. 1998) have been the only investigator to look at the microbiologic status of root filled teeth with normal periapices. He examined the microbiological status of 120 root-filled teeth: 100 with periradicular periodontitis and 20 with normal periapices. In this study, the prevalence of Enterococcus spp. in root filled teeth with apical lesions and those root filled teeth with a normal periapex was thirty-two and five percent respectively. While this study stands alone as a predictor of the true bacterial profile of root filled teeth without periradicular rarefactions, the study design has several weaknesses. The use of chloroform prior to bacterial sampling has been shown to reduce bacterial detection(Molander et al. 1998; Fouad and Barry 2005) . Furthermore, 26.6\% of the teeth with lesions in the Molander et al. study had no bacterial growth, indicating the low sensitivity of the culturing techniques used. In addition, a high percentage of lactobacillus were recovered among the positive cultures which may represent contamination. 
Thus there appears to be scarce evidence that Enterococcus species are truly unique to the failing root filling and not merely a commensal part of the root filled tooth. Therefore, it may be premature to focus antimicrobial therapies on eradicating one bacterial species which may not be solely responsible for endodontic pathosis. The hypothesis for this study is that Enterococcus spp. have a higher prevalence in root canal treated teeth with periradicular lesions than those without periradicular rarefaction. If this hypothesis is shown to be true, then this microorganism would be a primary suspect in the pathogenesis of periradicular lesions, thereby causing endodontic failure.

\section{MATERIALS AND METHODS}

\section{Patient Selection:}

All patient procedures were approved by the IRB \#04070 at University of Connecticut Health Center, and all patients provided written informed consent prior to being recruited in the study. Two groups of patients were recruited. The first group of patients had an endodontically-treated tooth with radiographic evidence of periradicular periodontitis requiring endodontic retreatment; the second group had an endodontically-treated tooth requiring retreatment but without radiographic evidence of apical pathosis. Cases in the second group were retreated due to suspected coronal leakage or prior to an extensive restoration when the technical quality of the previous treatment was questionable. Suspected coronal leakage and/or poor technical quality of 
previous treatment were also frequently present in the first group, except that the teeth in that group also had lesions. Teeth were included in the study only if the initial root filling was completed at least one year previously. Only permanent teeth of adult patients were included.

The following variables were registered for each patient: 1) Peri-operative signs and symptoms: defined as moderate to severe pain to percussion or palpation, or any flare-ups where the patient returns for unscheduled appointments with symptoms; 2) Quality of previous root filling; 3) Quality of the coronal restoration and 4) History of diabetes mellitus. The quality of the previous root filling was dichotomized into: acceptable (obturation $2 \mathrm{~mm}$ short of the apex or $0.5 \mathrm{~mm}$ long, with no voids more than $1 \mathrm{~mm}$ ) or unacceptable. Likewise, the quality of restoration was dichotomized such that acceptable were only those permanent restorations with adequate seal determined clinically and radiographically.

\section{Sampling Procedure}

Teeth were isolated using rubber dam and accessed. Disinfection with $30 \%$ hydrogen peroxide and $5 \%$ iodine tincture were carried out according to the protocol outline by Möller (Moller 1966). The teeth were further disinfected with $6 \%$ sodium hypochlorite $(\mathrm{Ng} 2003)$. If the tooth had caries, the disinfection steps were repeated and new sterile instruments were used following caries excavation. Sodium hypochlorite was neutralized with $5 \%$ sodium thiosulphate. At this point, a surface specimen was collected with paper points that was to be 
analyzed in case of a positive Enterococcus spp. result (see below). Root-filling material was removed using Gates Glidden drills, Hedstrom files and Profile $®$ rotary instruments with no solvent. Working length was estimated using a Root ZX and confirmed radiographically. All attempts were made to instrument canals to a length $0.5-1 \mathrm{~mm}$ short of the radiographic apex. Saline was introduced into the canal, once an apical size of 25 had been reached and most of the root filling material had been removed. The specimens were obtained using three paper points placed in the canal for about 30 seconds in succession. In addition, a new sterile \#25 H-file was used to length, and the working area of the file aseptically separated and added to the specimen. For multi-canalled cases, the sampling was performed from one canal and in the case of a tooth with a periradicular lesion the sample was taken from the root with the periradicular rarefaction. The paper points and file were transferred to sterile, DNA/RNA-free vials containing $1 \mathrm{~mL}$ filter-sterilized 10mM Tris-HCl; $1 \mathrm{mM}$ EDTA $(\mathrm{pH}=8)$ and $0.5 \mathrm{~g}(0.71-1.18 \mathrm{~mm})$ sterile glass beads. The vials were frozen at $-70^{\circ} \mathrm{C}$ until used.

\section{DNA extraction:}

The specimens were thawed and the vials with paper point specimens were vortexed for $2 \mathrm{~min}$ to disperse microbial cellular material into suspension. The suspension was transferred from the original vial to $2 \mathrm{ml}$ DNA/RNA-free sterile vials, which were centrifuged for 10 minutes at $7500 \mathrm{rpm}$, and the supernatant was removed. From the cellular pellet, DNA was extracted by the enzymatic extraction method, using the Qiagen-QIAamp DNA mini kit protocol (Qiagen, Valencia, CA). This was performed after suspending the pellet in $180 \mu \mathrm{L}$ 
of enzyme solution ( $20 \mathrm{mg} / \mathrm{ml}$ lysozyme; $20 \mathrm{mM}$ Tris $\mathrm{HCl}$, pH 8.0; 2 mM EDTA; $1.2 \%$ Triton), incubating it for $30 \mathrm{~min}$. at $37^{\circ} \mathrm{C}$, and adding Proteinase $\mathrm{K}(20 \square \mathrm{L})$ and Rnase $A(4 \mu \mathrm{L}$ at $100 \mathrm{mg} / \mathrm{mL})$ for 2 minutes at room temperature.

\section{PCR primers:}

All specimens were amplified with ubiquitous (broad range) bacterial primers that target the $16 \mathrm{~S}$ rRNA gene to determine bacterial presence, as described previously(Fouad et al. 2002). The following primers were used for this purpose: Forward: AGA GTT TGA TCC TGG CTC AG, and Reverse:ACG GCT ACC TTG TTA CGA CTT. In addition, genus-specific oligonucleotide primers were used to identify the Enterococcus spp. The following primers, which amplify a 112 bp sequence (Ke et al. 1999), were used to amplify enterococcal DNA sequences in the tuf gene: Forward: TAC TGA CAA ACC ATT CAT GAT G and Reverse: AAC TTC GTC ACC AAC GCG AAC. These primers have been shown to detect 14 species within the genus Enterococcus (Ke et al. 1999), and two Abiotrophia spp. were shown to be negative with 17 other endodontic pathogens(Fouad et al. 2002).

\section{PCR Assay:}

PCR amplification was performed in a PE9700 thermal cycler (Applied Biosystems, Foster City, CA). PCR conditions were generally as follows: the initial denaturation was at $94^{\circ} \mathrm{C}$ for $15 \mathrm{~min}$. This was followed by 35 cycles of denaturation at $94^{\circ} \mathrm{C}$ for $15 \mathrm{~s}$, annealing at $55^{\circ} \mathrm{C}\left(56^{\circ} \mathrm{C}\right.$ for ubiquitous primers $)$ for $15 \mathrm{~s}$ and extension at $72^{\circ} \mathrm{C}$ for $45 \mathrm{~s}$. The final extension was at $72 \mathrm{C}$ for 5 
$\min$, then the products were cooled to $4^{\circ} \mathrm{C}$ until removed(Fouad et al. 2002). The reaction was carried out in a volume of $50 \mu \mathrm{L}$ containing $5 \mu \mathrm{L}$ of extracted sample DNA, $5 \mu \mathrm{L}$ of $10 x$ PCR buffer, $0.5 \mu \mathrm{L}$ HotStar Taq, (Qiagen, Valencia, CA), $1.5 \mathrm{mM} \mathrm{MgCl}_{2}, 0.2 \mathrm{mM}$ of each of the 4 deoxynucleoside triphosphates (dNTP)

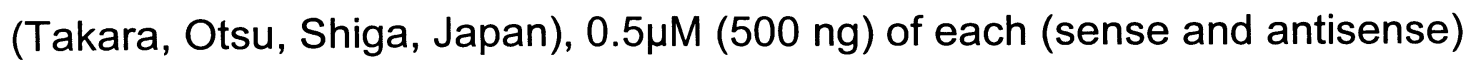
primer and the balance made up of sterile ultrapure water. All PCR experiments had positive (extracted E. faecalis DNA) and negative (ultrapure water) controls. Amplification products were analyzed by $2 \%$ agarose gel electrophoresis in Trisacetate EDTA (TAE) buffer (40 mM Tris-acetate, 2 mM EDTA, pH 8.3). Gels were stained with $0.5 \mu \mathrm{g} / \mathrm{mL}$ ethidium bromide for 30 minutes and destained with water for 15 minutes. The PCR products were visualized under UV light.

\section{Direct Sequencing of PCR products:}

In order to verify that the positive specimens did contain Enterococcus spp., and to determine which species were present, direct sequencing was performed on the Enterococcus-positive PCR products (Fouad 2003). For sequencing, the PCR products were reamplified, then purified using Marligen Bioscience Rapid PCR Purification System (Marligen Bioscience, Inc., ljamsville, MD.) Sequencing reaction mixes were prepared with forward and reverse Enterococcus primers, separately (11-32 ng DNA per reaction mix). Sequencing was performed by the Molecular Core Facility, at the University of Connecticut Health Center, using the ABI Prism 3100 Genetic Analyzer. Sequences were used to search databases available though NCBI, using the BLAST algorithm, 
then aligned and phylogenetically analyzed using MacVector 7.2 (Accelrys, San Diego, CA).

\section{Data Analysis:}

Designation of Lesion vs. no lesion:

Two experienced endodontists who were not involved in the treatment of the patients and who did not know the microbiological results reviewed periapical radiographs individually and rendered a decision of lesion or no lesion. In cases where there was a discrepancy between reviewers both individuals conferred together and a consensus was reached.

Prevalence:

The prevalence of bacteria and of Enterococcus spp. were recorded as the percentage of the cases examined. The prevalence values in cases with and without periradicular lesion were compared using the Chi square analysis. A significance level of $p>.05$ was used.

Sample size Determination:

A statistical power analysis had been performed to determine the optimal sample size. The prevalence of enterococci in cases with lesions was assumed to be about $70 \%$ based on recent data(Siqueira Junior 2004). Due to the scarcity of data on enterococci in cases with no lesions, we used a figure that was half the number of expected prevalence for cases with lesions, with an assumption that this difference would be clinically significant. Assuming a standard Type II 
error rate of beta $=.20$ (power $=1$ - beta $=.80)$, and a standard Type I error rate of alpha $=.05$, the effect size was calculated to be 0.72 . According to Cohen's textbook (Cohen 1988) a sample size of $n=24$ per group would be needed to yield statistical power of $80 \%$. We recognized that it was more difficult to recruit patients in the no lesion category than cases with lesions, and made an assumption based on the previous year's treated cases that there will be a 2:1 ratio between the sample sizes of the Lesion versus the No Lesion groups. Therefore we used $n^{`}=24$ as the harmonic mean of the groups needed to meet the criteria. The formula for $n^{`}=2\left(n_{1}\right)\left(n_{2}\right) /\left(n_{1}+n_{2}\right)$, was used to determine the sample needed in the No Lesion group $\left(n_{1}\right)$, and Lesion group $\left(n_{2}\right)$. This yielded a sample size of $n=18$ for the No Lesion group and $n=36$ for the Lesion group, for a minimum total $n=54$.

\section{RESULTS}

Sixty-five patients were recruited for the study; however, seven of those patients had been on antibiotic during some portion of the preceding two months so they were excluded from the analysis. Thus the final sample size was 58 , in which 22 cases had no periradicular lesions and 36 were with lesions.

Overall, bacteria were detected in 52 of 58 cases $(89.7 \%)$. They were present in all but one case in which lesions were present, and in 17 of 22 cases with no lesions (Table3) (odds ratio=10.3). Chi-Square analysis revealed a statistically significant relationship between lesion status and the presence of bacteria using the universal primers $(p=0.032)$. Teeth with a periradicular lesion 
were significantly more likely to have bacteria than teeth without a periradicular lesion.

Additional perameters were also evaluated. Restoration quality was not associated with lesion status (Table 4). Likewise, obturation quality was not associated with periapical health (Table 5).

Enterococcus spp. was present in only 7 of 58 cases or $12.1 \%$. Five cases with Enterococcus spp. were in cases with no lesions, while only two were in cases with lesions (Table 6)(odds ratio $=5$ ). A 2-sided fisher's exact test revealed a trend toward significance $(p=0.10)$.

Seven of the 58 cases included in this study were from diabetic patients; one from type 1 and 6 from type 2 diabetics. Four of these were in the non-lesion and three in the lesion groups. All cases from diabetic patients had bacteria detected in the root canal, but none of them had enterococci. Table 6 shows the other clinical parameters associated with the cases with or without enterococci. A logistic regression analysis was performed to control for the quality of restoration, quality of obturation, peri-operative symptoms, and history of diabetes. There was a statistically significant inverse relationship between presence of Enterococcus and lesion status $(\mathrm{p}=0.023)$. Enterococcus spp. was associated with non-lesion teeth. Controlling factors failed to predict likelihood of Enterococcus spp. alone or collectively but when controlling for them, they allowed lesion status (lack of a demonstrable lesion) to be a strong predictor of Enterococcus spp. recovery. Using sequential entry of independent variables none of the four independent variables (the quality of restoration, quality of 
obturation, peri-operative symptoms, and history of diabetes) was shown to be statistically significantly related to the dependent variable, recovery of

Enterococcus spp., nor were they collectively able to account for the presence of a periradicular lesion.

The type of obturation material encountered upon retreatment was also recorded. All of the teeth treated had been obturated with gutta percha except one that contained a silver point. Enterococcus was not recovered from the patient sample containing a silver point. Only four patients presented with preoperative sinus tracts, therefore, these two variables were not used in the statistical analysis.

The phylogenetic analysis of the identity of the seven positive specimens revealed that they formed a clade that had its closest match with E. faecalis V583 (AE016947) (Fig. 1). Examination of the control external specimens from the seven Enterococcus-positive canal specimens revealed a positive reaction in only one of them.

\section{DISCUSSION}

This study showed that the prevalence of Enterococcus spp. in the root canals of cases receiving endodontic retreatment was $12.1 \%$. This prevalence is lower than that previously reported in some studies $64-77 \%$ (Rocas and Jung 2004; Siqueira Junior 2004) using PCR identification, but is consistent with the $22 \%$ reported in an earlier study by our group(Fouad and Barry 2005). In fact an earlier molecular study (Rolph et al. 2001), and one culture study (Cheung and Ho 2001) failed to identify enterococci in retreatment cases. Enterococci are 
capable of surviving for long durations under adverse circumstances (Figdor 2003), and in the treated root canal environment their presence may be related to their overall presence in the mouth(Engstrom 1964). Certainly, many cases with lesions had bacteria in the root canals, but no enterococci.

The identity match of the enterococci sequenced in this study were similar to those identified in our previous study, in which the same molecular detection techniques were used(Fouad and Barry 2005). The elongation factor Tu (tuf) gene is not as well characterized as the $16 \mathrm{~S}$ gene to be used for bacterial identification in general, but can be used to screen sequences within a smaller group of microorganisms. The prevalence of Enterococcus spp. in this study, however, was lower than the $22 \%$ reported in our previous study of 37 retreatment cases with periradicular lesions(Fouad and Barry 2005). The difference between the overall prevalence of this microorganism in the two studies was not statistically significant (Chi-square; $p=0.213$ ). However, if only the cases with lesions in this study are considered $(n=36$, with two specimens positive for Enterococcus spp.), then the difference between the studies is significant (Chi-square; $p=0.046$ ). This apparent difference between the studies may be related to the fact that in the previous study the microbial specimens were incubated in thioglycollate broth prior to performing the molecular techniques. This may have allowed more enterococci to grow and thus improved the overall detection sensitivity. However, this difference is not relevant to the main findings of this study, since the same techniques were used for both groups examined. 
Molecular studies cannot be directly compared, particularly if different oligonucleotide primers are used, due to potential differences in primer sensitivity or optimization of reactions. Thus, the differences between the findings of this study and the high values reported previously (Rocas and Jung 2004; Siqueira Junior 2004)could be due to differences in primer sensitivity. Therefore, a pilot study was performed prior to analysis of patient samples. Known concentrations of bacterial cells of an ATCC stock strain of E. faecalis (19433) were analyzed using the PCR primer published in those studies and the primers used in this study. The primers, used in this study, were found to be 10 -fold more sensitive than those reported previously. Thus, primer sensitivity could not explain the differences in recovery rates between this study and those reported previously.

It is possible that the differences seen in prevalence of this microorganism are due to geographical differences in the prevalence of enterococci in the mouth, a factor that was recently recognized in the endodontic literature(Baumgartner and Siqueira Junior 2004). In any case, the design of this study was such that primer sensitivity was an irrelevant factor since all specimens from cases with and without lesions were analyzed using the same conditions.

Unlike culture modalities, PCR measures the presence of DNA. Therefore, disinfection procedures for PCR sampling are unique compared to those for culture. Complete removal of all traces of DNA is a formidable challenge. Very little has been written about definitive disinfection procedures for reliable removal of DNA. An in vivo study of decontamination of the operating 
field using either $10 \%$ iodine or $2.5 \% \mathrm{NaOCl}$ revealed a recovery rate of bacterial DNA using PCR in $45 \%$ and $13 \%$ respectively (Ke et al. 1999). Thus an effort was made in our experiment to improve disinfection procedures and minimize contamination by using a higher concentration of $\mathrm{NaOCl} 6 \%$ in addition to iodine and $\mathrm{H}_{2} \mathrm{O}_{2}$. Despite, our strict aseptic technique and our thorough disinfection process one of the control samples taken from the chamber revealed enterococcal DNA. This tooth also tested positive for Enterococcus within the canal system. Hence, the uncertainty exists how much contamination exists in studies where weaker dilutions of $\mathrm{NaOCl}$ and no iodine were used. Clearly more studies will be needed to elucidate the answer.

One of the observations of this experiment was a statistically higher recovery of bacteria, using a broad range $16 \mathrm{~S}$ bacterial primers, in teeth with periradicular pathosis. This is consistent with the established belief that periapical disease is due to a bacterial etiology(Kakehashi et al. 1965; Sjögren et al. 1997).

It has recently been speculated that Enterococcus spp. may play a role in endodontic failure due to its low recovery in primary infections and higher recovery in secondary infections(Molander et al. 1998). However, the results of this experiment suggest otherwise. Surprisingly, when possible confounding factors were controlled for, there was a statistically higher number of teeth without periradicular lesions which were found to harbor this bacteria compared to teeth with periradicular lesions. One explanation might be that the teeth without periradicular pathosis might be in the process of developing a periradicular lesion. These explanations were accounted for in the study design. 
Non-lesion teeth were included in the study only if obturation had been completed more than one year previously. The range of time from obturation to retreatment for patients who tested positive for Enterococcus spp. was between 2 and 28 years (mean $=11.7$ years.)

The results of this study are strengthened by the large sample size obtained in comparison to the only other published molecular studies measuring the incidence of Enterococcus in retreatment cases. Our sample size was 58 compared to 37 in the Fouad study (Fouad and Barry 2005), 22 in the Siquera study (Siqueira Junior 2004), 14 in the Rocas study (Rocas and Jung 2004) and only 11 in the Rolph study (Rolph et al. 2001). A power analysis was performed prior to the initiation of our study to insure an adequate sample size would be recruited to effectively draw clinically relevant conclusions.

Enterococcus faecalis is a normal intestinal organism and may inhabit the oral cavity and gingival sulcus (Engstrom 1964; Sedgley and Lennan 2004). In its intestinal environment, it is considered a commensal organism that contributes to carbohydrate, amino acid and vitamin metabolism. However, a subset of this species appear to be pathogenic because they have acquired a number of genes conferring infectivity and virulence, including resistance to multiple antibiotics (Gilmore 2003). The high-molecular weight surface protein Esp, has been found in high frequencies among enterococcal isolates associated with urinary tract infections and endocarditis(Shankar 2001). This surface antigen may aid in the ability of this bacteria to adhere to the lining of the heart and form biofilms. Production of other factors such as cytolysin, hyaluranidase and gelatinase have 
been linked to host tissue damage(Kayaoglu 2004). It is known that Enterococcus can cause serious disease processes in certain areas of the body while in others exist without detriment. The presence of this bacteria within the oral cavity is not associated with disease in itself and it is becoming more evident that its role in periapical disease may be minor.

A direct correlation has been demonstrated between the occurrence of enterococci in the oral cavity and pulp cavity (Engstrom 1964). The same bacterial type cultivated from proximal spaces consistently matched those recovered from the tonsil and root canal samples in the same patient (Engstrom 1964). Although $E$. faecalis is found within the oral cavity its recovery rate differs between populations of individuals. Oral rinse samples, obtained from 100 patients receiving endodontic therapy and 100 dental students with no history of endodontic treatment, revealed E. faecalis to be present in $11 \%$ and $1 \%$, respectively (Sedgley and Lennan 2004).

It is feasible that if inoculation of enterococci occurs during initial root canal therapy or due to subsequent microleakage these microorganisms will persist in the root canal far after other bacteria have died, due to their fastidious nature(Figdor 2003). E. faecalis was shown to be capable of withstanding high $\mathrm{pH}$ changes as well as prolonged periods of little to no nutrients (Orstavik and Haapasalo 1990). Despite its adept ability to accommodate to the surrounding environment, E. faecalis does not seem to exhibit significant pathogenic qualities within the root canal system as a monoinfection. 
In a monkey study in which enterococci were inoculated into monkey teeth only 2 of 9 cases developed radiographically-demonstrable periradicular lesions within six months (Fabricius et al. 1982). Closer examination of the possible mechanism of interaction between $E$. faecalis and the human immune cells revealed that inflammatory mediators responsible for osteolysis were actually decreased in the presence of these bacteria. Sonicated E. faecalis extracts were exposed to human T cells and the amount of interleukin-2 and Intereleukin-4 production were measured (Ho-Hyun et al. 2004). Enterococcus decreased these immune mediators. According to this premise the presence of $E$. faecalis should decrease the incidence of periapical bone destruction. This mechanism is consistent with the findings of our study where $E$. faecalis was found to be associated with the lack of periapical breakdown.

E. faecalis alone does not appear to be a major player in the development of periapical disease but it may have an indirect role on other bacteria that may be detrimental to periapical health. Recently it was shown that E. faecalis may indirectly increases the survival and the pathogenicity of other bacteria in the root canal system (Moller and Fabricius 2004).

The unprecedented findings of this study belie the question: "Are Enterococcus spp. important in periradicular pathology or merely opportunistic bystanders?". The results of this study may serve as a means of redirecting efforts away from just the eradication of enterococci and toward addressing the polymicrobial pathogens involved in periradicular pathosis. 
Table 1. Enterococcus faecalis recovered at time of retreatment: culture studies.

\begin{tabular}{|c|c|}
\hline Frerquency & Study \\
\hline $\mathbf{2 7 \%}$ & Moller, Odontol Tidskr 1966 \\
\hline $\mathbf{3 2 \%}$ & Molander el al., IEJ 1998 \\
\hline $\mathbf{3 8 \%}$ & Sundqvist el al., OOO \\
\hline $\mathbf{5 6 \%}$ & Peciuliene et al., JOE 2000 \\
\hline $\mathbf{3 0 \%}$ & Hancock et al., OOOOE \\
\hline $\mathbf{3 7 \%}$ & Pinheiro et al., OMI 2003 \\
\hline $\mathbf{0 \%}$ & Cheung \& Ho, IEJ 2001 \\
\hline
\end{tabular}


Table 2. E faecalis recovered at time of retreatment: molecular studies

\begin{tabular}{|c|c|}
\hline Frequency & Study \\
\hline $\mathbf{0 \%}$ & $\begin{array}{r}\text { Rolph et al., J Clin Micro 2001 } \\
(\mathrm{n}=11)\end{array}$ \\
\hline $\mathbf{7 7 \%}$ & $\begin{array}{r}\text { Siquera el al., OOOOE 2004 } \\
(\mathrm{n}=22)\end{array}$ \\
\hline $\mathbf{6 4 \%}$ & $\begin{array}{c}\text { Rocas et al., JOE 2004 } \\
(\mathrm{n}=14)\end{array}$ \\
\hline $\mathbf{2 3} \%$ & $\begin{array}{r}\text { Fouad et al., OOOOE 2005 } \\
(\mathrm{n}=37)\end{array}$ \\
\hline
\end{tabular}


Table 3 Bacteria presence using a universal primer and lesion status

\begin{tabular}{|c|c|c|c|}
\hline & Bacteria Present & Bacteria Absent & Total \\
\hline Lesion Present & 35 & 1 & 36 \\
\hline Lesion Absent & 17 & 5 & 22 \\
\hline & & & 58 \\
\hline
\end{tabular}


Table 4: Bacterial presence using a universal primer in relation to lesion status and restoration quality.

\begin{tabular}{|c|c|c|c|c|}
\hline & & $\begin{array}{c}\text { Bacteria } \\
\text { Present }\end{array}$ & $\begin{array}{c}\text { Bacteria } \\
\text { absent }\end{array}$ & \multirow{2}{*}{ Totals } \\
\hline \multirow{2}{*}{$\begin{array}{c}\text { Lesion } \\
\text { Present }\end{array}$} & Adequate Restoration & $\mathbf{2 1}$ & $\mathbf{0}$ & \multirow{2}{*}{36} \\
\cline { 2 - 4 } & Inadequate Restoration & 14 & 1 & \\
\hline Lesion & Adequate Restoration & $\mathbf{9}$ & 3 & \multirow{2}{*}{22} \\
\cline { 2 - 5 } Absent & Inadequate Restoration & $\mathbf{8}$ & $\mathbf{2}$ & \multirow{2}{*}{58} \\
\hline
\end{tabular}


Table 5 Bacterial presence in relation to restoration quality and obturation quality.

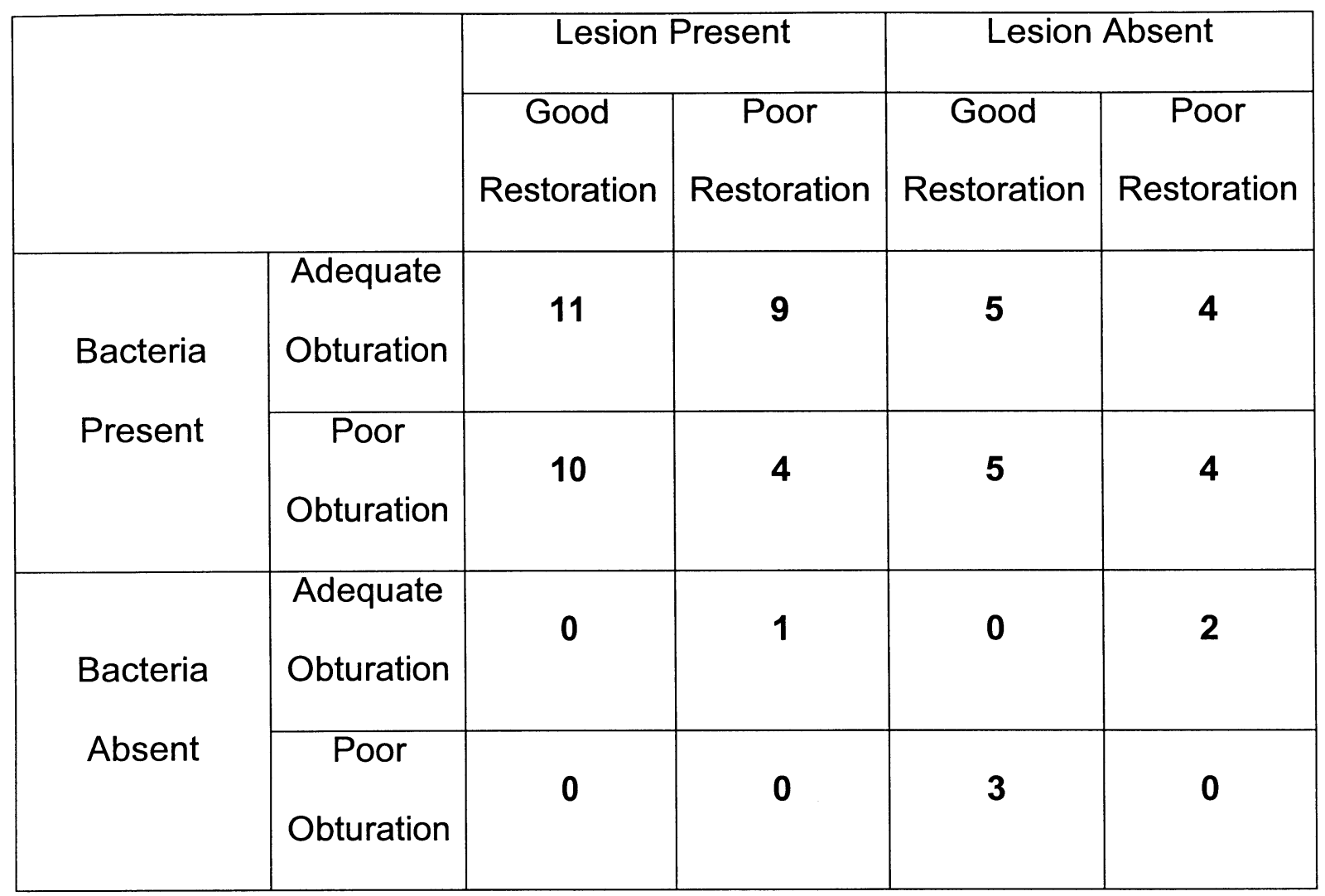


Table 6: Clinical parameters of cases in which Enterococcus spp. was identified:

\begin{tabular}{|l|c|c|c|c|}
\hline Lesion & Quality of & Quality of & Peri-operative & $\begin{array}{c}\text { Number of } \\
\text { status }\end{array}$ \\
Restoration & Obturation & $\begin{array}{c}\text { snterococcus spp.- } \\
\text { positive cases }\end{array}$ \\
\hline Present & Adequate & Adequate & Absent & 1 \\
\hline Present & Adequate & Inadequate & Present & 1 \\
\hline Absent & Adequate & Adequate & Absent & 1 \\
\hline Absent & Adequate & Inadequate & Absent & 2 \\
\hline Absent & Inadequate & Adequate & Present & 2 \\
\hline
\end{tabular}


Method: Neighbor Joining; Best Tree; tie breaking = Systematic

Distance: Kimura 2-parameter; Gamma correction $=0$ ff

Transition:Transversion Ratio $=$ Estimate $($ Av. $=0.96)$;

Gaps distributed proportionally

E. cecorum AF 274718

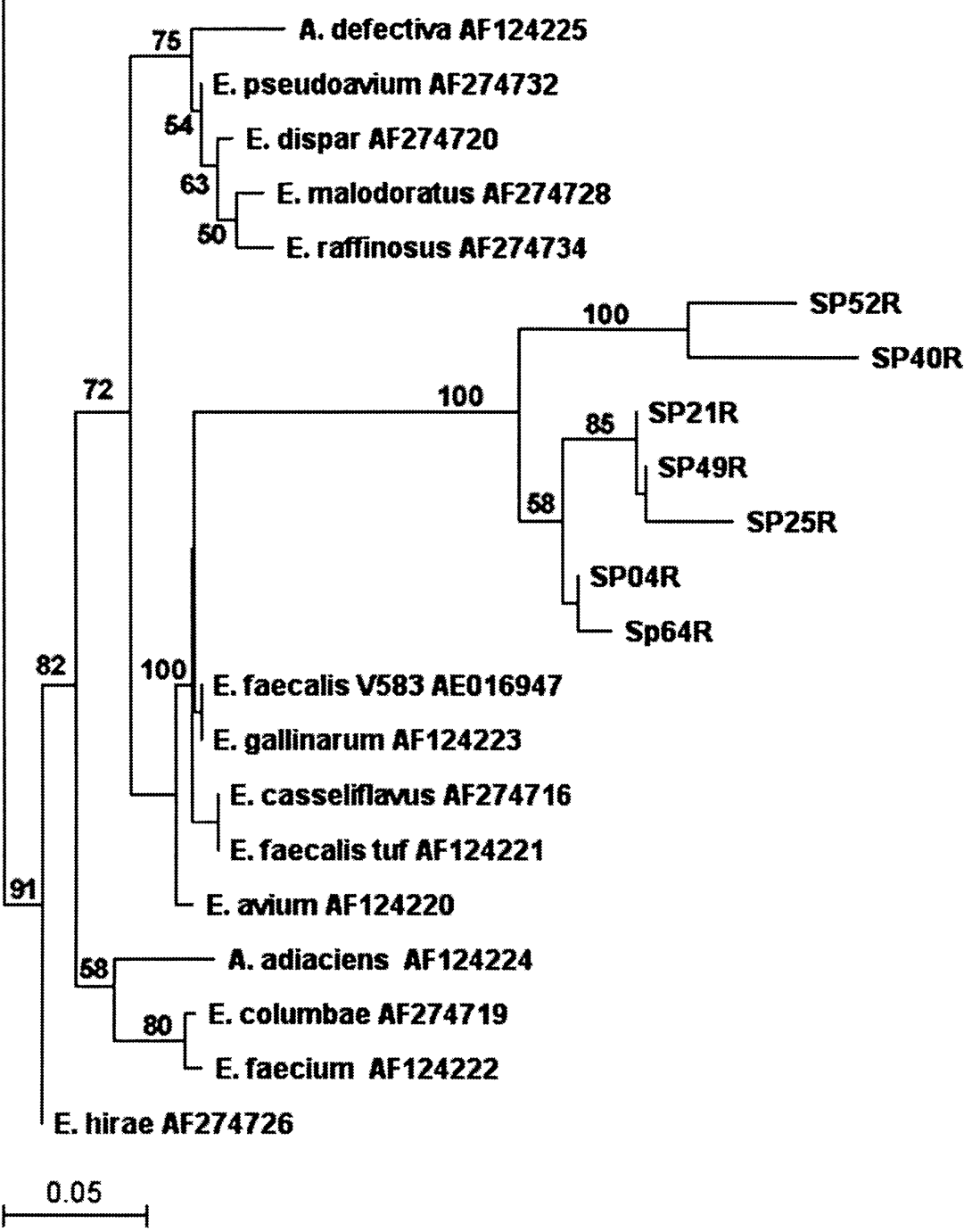


Figure Legend:

Figure 1: Dendrogram showing phylogenetic analysis of seven positive Enterococcus spp. specimens. This diagram represents the accepted method for describing the evolutionary relationship of organisms based on their DNA profiles. It is used to determine relatedness of organisms and thus aid in their identification. The numbers denote a boot strap analysis with 100 repetitions, which represent the chances that these phylogenetic relationships are absolute. The two genera represented are Enterococcus and Abiotrophia. 


\section{REFERENCES}

Baker, N., F. R. Liewehr, T. B. Buxton and A. P. Joyce (2004). "Antibacterial efficacy of calcium hydroxide, iodine potassium iodide, betadine, and betadine scrub with and without surfactant against $E$ faecalis in vitro." Oral Surg Oral Med Oral Pathol 98: 359-364.

Baumgartner, C. J. and J. F. Siqueira Junior (2004). "Geographical differences in bacteria detected in endodontic infections using polymerase chain

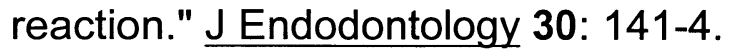

Blayney, J. (1927). "The biologic aspects of root canal therapy." Dent Items 49: 681.

Buckley, J. P. (1906). "The rational treatment of putrescent pulps and their sequellae." Dent Cosmos 48: 537.

Bystrom, A. and G. Sundqvist (1981). "Bacteriologic evaluation of the efficacy of mechanical root canal instrumentation in endodontic therapy." Scandinavian Journal of Dental Research 89(4): 321-8.

Chavez de Paz Villanueva, L. E., Dahlen A., Molander A., Moller, A., Bergenholtz G. (2003). "Bacteria recovered from teeth with apical periodontitis after antimicrobial endodontic treatment." International Endodontic Journal 36: 500-508.

Cheung, G. S. and M. W. Ho (2001). "Microbial flora of root canal-treated teeth associated with asymptomatic periapical radiolucent lesions." Oral Microbiol Immunol 16(6): 332-337.

Cohen, J. (1988). Statistical power analysis for the behavioral sciences. Hillsdale, $\mathrm{NJ}$ :, Lawrence Erlbaum Associates.

Dahlen, G. and G. Bergenholtz (1980). "Endotoxic activity in teeth with necrotic pulps." Journal of Dental Research 59(6): 1033-40. 
Dahlen, G., W. Samuelsson, A. Molander and C. Reit (2000). "Identification and antimicrobial susceptibility of enterococci isolated from the root canal." Oral Microbiol Immunol 15(5): 309-12.

Delivanis, P. D. and V. S. Fan (1984). "The localization of blood-borne bacteria in instrumented unfilled and overinstrumented canals." J Endod 10(11): 5214.

Engstrom, B. (1964). "The significance of enterococci in root canal treatment." Odontologisk Revy 15: 87-106.

Engström, B., L. Hård Af Segerstad, G. Ramström and G. Frostell (1964). "Correlation of positive cultures with the prognosis of root canal treatment." Odontologisk Revy 15: 257-70.

Evans, M., J. K. Davies, G. Sundqvist and D. Figdor (2002). "Mechanisms involved in the resistance of Enterococcus faecalis to calcium hydroxide." Int Endod J 35(3): 221-8.

Fabricius, L., G. Dahlen, S. E. Holm and A. J. Moller (1982). "Influence of combinations of oral bacteria on periapical tissues of monkeys." Scand $\mathrm{J}$ Dent Res 90(3): 200-6.

Figdor, D., Davies, J.K., Sundqvist, G. (2003). "Starvation survival, growth and recocvery of Enterococcus faecalis in human serum." Oral Microbiol Immunol 18: 234-239.

Fisher, R. and J. Huerta (1984). "Effect of pH on microbial flora of necrotic root canals." J Endodontology 10: 153-5.

Fouad, A., Kum, K.Y.,Clawson, M.L., Barry, J., Abenoja, C. Zhu, Q., Caimano, M., RAdolf, J.D. (2003). "Molecular characterization of the presenence of Eubacterium spp and Streptococcus spp in endodontic infections." Oral Microbiol Immunol 18: 249-55.

Fouad, A. F. and J. Barry (2005). "The effect of antibiotics and endodontic antimicrobials on the polymerease chain reaction." $\mathrm{J}$ Endodontology (in press). 
Fouad, A. F., J. Barry, M. Caimano, M. Clawson, Q. Zhu, R. Carver, K. Hazlett and J. D. Radolf (2002). "PCR-based identification of bacteria associated with endodontic infections." J Clin Microbiol 40(9): 3223-31.

Fouad, A. F. and J. Burleson (2003). "The effect of diabetes mellitus on endodontic treatment outcome: data from an electronic patient record." JADA 134(1): 43-51.

Gier, R. E. and D. F. Mitchell (1968). "Anachoretic effect of pulpitis." Journal of Dental Research 47(4): 564-70.

Gilmore, G. S., Ferretti, J.J. (2003). "The thin line between gut commensal and pathogen." Science 299: 1999-2002.

Haapasalo, M. (1989). "Bacteroides spp. in dental root canal infections." Endod Dent Traumatol 5(1): 1-10.

Heling, B. and J. Shapira (1978). "Roentgenologic and clinical evaluation of endodontically treated teeth, with or without negative culture." Quintessence International 9(11): 79-84.

Hems, R. S., K. Gulabivala, Y.-L. Ng, D. REady and D. Spratt (2005). "An in vitro evaluation of the ability of ozone to kill a strain of Enterococcus faecalis." Int Endod J 38: 22-29.

Ho-Hyun, S., L. SungSam, S. WonJun, K. Hyeon-Sik and L. WooCheol (2004). "Effects of sonicated Enterococcus faecalis extracts on interleukin-2 and interleukin-4 production by human T cells." J Endodontology 30: 701-703.

Kakehashi, S., H. R. Stanley and R. J. Fitzgerald (1965). "The effects of surgical exposures of dental pulps in germfree and conventional laboratory rats." Oral Surg Oral Med Oral Pathol 20: 340-8.

Kayaoglu, G. a. O., D. (2004). "Virulence factors of Enterococcus Faecalis: relationship to endodntic disease." Crit Rev Oral Biol Med 15(5): 308-320.

Ke, D., F. J. Picard, F. Martineau, C. Menard, P. H. Roy, M. Ouellette and M. G. Bergeron (1999). "Development of a PCR assay for rapid detection of enterococci." J Clin Microbiol 37(11): 3497-503. 
Molander, A. and G. Dahlen (2003). "Evaluation of the antibacterial potential of tetracycline or erythromycin mixed with calcium hydroxide as intracanal dressings against Enterococcus faecalis in vivo." Oral Surg Oral Med Oral Pathol 96: 744-50.

Molander, A., C. Reit, G. Dahlen and T. Kvist (1998). "Microbiological status of root-filled teeth with apical periodontitis." Int Endod J 31(1): 1-7.

Moller, A. (1966). "Microbial examination of root canals and periapical tissues of human teeth." Odontol Tidskift 74: 1-380.

Moller, A. J. and L. Fabricius (2004). "Apical periodontitis development and bacterial response to endodontic treatment. Experimental root canal infections in monkeys with selected bacteria strains." Eur J Oral Sci 112: 207-215.

Moller, A. J., L. Fabricius, G. Dahlen, A. E. Ohman and G. Heyden (1981). "Influence on periapical tissues of indigenous oral bacteria and necrotic pulp tissue in monkeys." Scandinavian Journal of Dental Research 89(6): 475-84.

Ng, Y., Spratt, D., Sriskantharajah, S., Gulabicala, K. (2003). "Evaluation of Protocols for field decontamination before bacterial sampling of root canals for contemporary microbial techniques." J Endodontology 29: 317320.

Onderdonk, T. (1901). "The treatment of unfilled root canals." Int Dent J 22: 20.

Orstavik, D. and M. Haapasalo (1990). "Disinfection by endodontic irrigants and dressings of experimentally infected dentinal tubules." Endod Dent Traumatol 6(4): 142-9.

Peciuliene, V., A. H. Reynaud, I. Balciuniene and M. Haapasalo (2001). "Isolation of yeasts and enteric bacteria in root-filled teeth with chronic apical periodontitis." Int Endod J 34(6): 429-34.

Ray, H. A. and M. Trope (1995). "Periapical status of endodontically treated teeth in relation to the technical quality of the root filling and the coronal restoration." Int Endod J 28(1): 12-8. 
Robinson, H. B. G. and L. R. Boling (1941). "The anachoretic effect in pulpitis. I. Bactereialogic studies." Journal of the American Dental Association 28: 268-282.

Rocas, I. N. and I. Y. Jung (2004). "Polymerase chain reaction identification of microorganisms in previously root-filled teeth in a Korean population." $\underline{\mathrm{J}}$ Endodontology 30: 504-508.

Rolph, H. J., A. Lennon, M. P. Riggio, W. P. Saunders, D. MacKenzie, L. Coldero and J. Bagg (2001). "Molecular identification of microorganisms from endodontic infections." J Clin Microbiol 39(9): 3282-9.

Safavi, K., P. Horsted, E. A. Pascon and K. Langeland (1985). "Biological evaluation of the apical dentin chip plug." J Endod 11(1): 18-24.

Sedgley, C. M. and S. L. Lennan (2004). "Prevalence, phenotype and genotype of oral enterococci." J Clin Microbiol.(19): 95-101.

Shabahang, S., Torabinejad M. (2003). "Effect of MTAD on Enterococcus faecalis-contaminated root canals of extracted human teeth." $\underline{J}$ Endodontology 29: 576-9.

Shankar, V. L., C. Baghdayan, A. Drachenberg, C. Gilmore, M. Johnson, D. (2001). "Role of Enterococcus faecalis surface protein Esp in the pathogenesis of ascending urinary tract infections." Infect Immun 69: 4366-4372.

Siqueira Junior, J. F., Rocas IN. (2004). "Polymerase chain reaction-based analysisof microorganisms associated with failed endodontic treatment." Oral Surg Oral Med Oral Pathol 97: 85-94.

Siqueira Junior, J. F., Rocas IN. (2004). "Polymerease chain reaction-based analysis of microorganisms associated with failed endodontic treatment." Oral Surg Oral Med Oral Pathol 97: 85-94.

Siren, E. K., Haapasalo, M.M.P., Waltimo, T.M.T., Orstavik, D. (2004). "In vitro antibacteerial effect of calcium hydroxide combined with chlorhexidine pr iodine potassium iodide on Enterococcus faecalis." European Journal of Oral Sciences 112: 326-331. 
Sjögren, U., D. Figdor, S. Persson and G. Sundqvist (1997). "Influence of infection at the time of root filling on the outcome of endodontic treatment of teeth with apical periodontitis." Int Endod J 30(5): 297-306.

Sjögren, U., B. Hagglund, G. Sundqvist and K. Wing (1990). "Factors affecting the long-term results of endodontic treatment." J Endod 16(10): 498-504.

Strindberg, L. L. (1956). "The dependence of the results of pulp therapy on certain factors." Acta Odontol Scand 14(Supp. 21): 175.

Sundqvist, G. (1976). Bacteriological studies of necrotic dental pulps (odontological dissertation no. 7). Umea, Sweden, University of Umea.

Sundqvist, G. (1992). "Associations between microbial species in dental root canal infections." Oral Microbiol Immunol 7(5): 257-62.

Sundqvist, G. (1992). "Ecology of the root canal flora." J Endod 18(9): 427-30.

Sundqvist, G. (1994). "Taxonomy, ecology, and pathogenicity of the root canal flora." Oral Surg Oral Med Oral Pathol 78(4): 522-30.

Sundqvist, G., D. Figdor, S. Persson and U. Sjogren (1998). "Microbiologic analysis of teeth with failed endodontic treatment and the outcome of conservative re-treatment." Oral Surg Oral Med Oral Pathol Oral Radiol Endod 85(1): 86-93.

Sundqvist, G., E. Johansson and U. Sjogren (1989). "Prevalence of blackpigmented Bacteroides species in root canal infections." J Endod 15(1): 13-9.

Sundqvist, G. K., M. I. Eckerbom, A. P. Larsson and U. T. Sjogren (1979). "Capacity of anaerobic bacteria from necrotic dental pulps to induce purulent infections." Infection \& Immunity 25(2): 685-93.

Torneck, C. D. (1966). "Reaction of rat connective tissue to polyethylene tube implants. I." Oral Surg Oral Med Oral Pathol 21(3): 379-87. 
Torneck, C. D. (1967). "Reaction of rat connective tissue to polyethylene tube implants. Part I." Oral Surg Oral Med Oral Pathol 21: 379.

Tronstad, L., J. O. Andreasen, G. Hasselgren, L. Kristerson and I. Riis (1980). "pH changes in dental tissues after root canal filling with calcium hydroxide." J Endod 7(1): 17-21.

Turner, S., R. M. Love and K. M. Lyons (2004). "An in-vitro investigation of the antibacterial effect of nisin in root canals and canal wall radicular dentine." Int Endod J 37: 664-671.

van Winkelhoff, A. J., A. Carlee and J. deGraaff (1985). "Bacteroides endodontalis and other black- pigmented Bacteroides species in odontogenic abscesses." Infect Immun 49: 494F.

Zerella, J. (2003). "Influence of chlorhexidine digluconate as a mixing vehicle on the antimicrobial effectiveness of calcium hydroxide solutions." Masters Thesis University of Connecticut. 